\title{
PENERAPAN PENDEKATAN CTL UNTUK MENINGKATKAN KAPASITAS BERPIKIR KRITIS MATEMATIK PESERTADIDIK DI TINGKAT SMP
}

\author{
Eko Agustianto ${ }^{1}$, Ikeu Ruhiyati ${ }^{2}$ \\ IKIP Siliwangi, Jalan Terusan Jenderal Sudirman, Cimahi, Jawa Barat, Indonesia \\ 1, xo.shirogane12@gmail.com, ${ }^{2}, \underline{\text { ikeuruhiyat@gmail.com }}$
}

\begin{abstract}
The research objective is to examine the achievement of mathematical critical thinking capacity of students applying the CTL approach with a comparison of students applying ordinary learning and examining the extent to which the increasing capacity of critical thinking in mathematics students apply the CTL approach to the comparison of students who apply ordinary learning. The study population was all junior high schools in West Bandung regency, were chosen arbitrarily and were selected by Darul Hikmah Junior High School. The sample is taken by any selected class of class 7-A as a research class, and class 7-B as a review class. The research class is given a learning model with the CTL approach, and the review class is given an ordinary learning model. The research instruments used in mathematical critical thinking capacity tests take the form of descriptions. Data processing increases the capacity of critical thinking mathematically by applying tests that distinguish two means using IBM SPSS 23 software. Data from the analysis showed that the achievement and improvement of the critical thinking capacity of the mathematics of the participants who were given the learning method using the CTL approach was better than those of the participants who were given the usual learning method.
\end{abstract}

Keywords: CTL (Contextual Teaching and Learning), Critical Thinking Skills Mathematics

\begin{abstract}
Abstrak
Penelitian ini bertujuan untuk menelaah pencapaian kapasitas berpikir kritis matematik pesertadidik yang mengaplikasikan pendekatan CTL dengan perbandingan pesertadidik yang mengaplikasikan pembelajaran biasa, dan menelaah peningkatan kapasitas berpikir kritis matematik pesertadidik yang mengaplikasikan pendekatan CTL dengan perbandingan pesertadidik yang mengaplikasikan pembelajaran biasa. Populasi dalam penelitian ini yaitu seluruh SMP di Kabupaten Bandung Barat, dipilih secara sembarang dan terpilihlah SMP Darul Hikmah. Sampel penelitian diambil secara sembarang kelas, dan terpilih kelas 7-A sebagai kelas riset serta kelas 7-B sebagai kelas peninjauan. Kelas riset diberikan metode pembelajaran dengan pendekatan CTL dan kelas peninjauan akan diberikan metode pembelajaran biasa. Instrumen penelitian yang digunakan dalam tes kapasitas berpikir kritis matematik berbentuk soal tes uraian sebanyak 5 soal. Pengolahan data peningkatan kapasitas berpikir kritis matematik ini menggunakan tes yang membedakan dua rerata dengan berbantu software IBM SPSS 23. Data hasil analisis memperlihatkan bahwa pencapaian dan peningkatan kapasitas berpikir kritis matematik pesertadidik yang diberikan metode pembelajaran dengan pendekatan CTL lebih baik berbanding pesertadidik yang diberikan metode pembelajaran biasa.
\end{abstract}

Kata Kunci: Pendekatan CTL, Berfikir Kritits Matematik.

Cara Mengutip: Agustianto, E., Ruhiyati, I. (2018). Penerapan Pendekatan CTL (Kontekstual) untuk Meningkatkan Kapasitas Berpikir Kritis Matematik Pesertadidik di Tingkat SMP. JPMI - Jurnal Pembelajaran Matematika Inovatif, 1 (6), 1063-1070. 


\section{PENDAHULUAN}

Matematika merupakan pelajaran wajib dan menjadi dasar disetiap pendidikan formal dari pendidikan sekolah yang paling rendah sampai tingkat pendidikan sekolah yang paling tinggi, baik itu matematika sederhana maupun matematika yang sulit untuk diselesaikan oleh pesertadidik. Menurut karena menurut Afrilianto (2012), "Matematika berfungsi untuk pengembangan berbagai aspek ilmu lainnya, dan matematika juga menjadi dasar teknologi modern yang ada di zaman ini". Bisa dibilang matematika merupakan suatu ilmu dari salah satu mata pelajaran yang bersifat universal (menyeluruh).

Matematika sangat diperlukan bagi setiap kalangan terutama untuk pesertadidik dari mulai tingkat dasar (sedini mungkin), yaitu untuk salah satu dasar pesertadidik dalam mengunakan kapasitas berpikir kritis ataupun kreatif, dan mendasari suatu sikap saling membantu dengan baik. Keberhasilan dalam nemerapkan pembelajaran matematika salah satunya yaitu pencapaian kapasitas berpikir kritis matematik pesertadidik yang meningkat. Rohaeti (2008) berpendapat, "Berpikir kritis matematika ialah bukti kecakapan sistematis dan kecermatan untuk menggabungkan pengetahuan awal, kemampuan penalaran matematik, dan strategi kognitif dalam memecahkan suatu permasalahan matematik". Hal itu didukung oleh Gokhaleb (Ramdhani, 2016), "Berpikir kritis menghubungkan dengan buah pemikiran dari Benjamin S. Bloom yaitu, soal berpikir kritis adalah soal yang melibatkan analisis, sintesis, serta pertimbangan dari suatu konsep". Menurut Sumarmo, (2012) indikator berpikir kritis matematik, yaitu:

1. Memusatkan pikiran pada permasalahan

2. Mengkaji dan mengolongkan permasalahan, penyelesaian, dan pendapat.

3. Memperhitungkan sumber yang dapat dipercaya

4. Memantau dan mengkaji dedukasi dan induksi

5. Merumuskan eksplanatori, kesimpulan, dan hipotesis

6. Menyusun pertimbangan

7. Mempertimbangkan keadaan matematis secara reflektif

8. Memperhitungkan keterangan disertai kecermatan, kesamaan, kepercayaan, ketegapan, dan bias

9. Menentukan sumber yang dapat dipercaya

10. Membedakan yang saling berkaitan dan yang tidak saling berkaitan

11. Mengidentifikasi dan menganalisis asumsi

12. Memeriksa kebenaran dari sebuah pendapat atau proses

Pentingnya mengembangkan dan membiasakan pesertadidik untuk menggunakan kapasitas berpikir kritis matematik merupakan tugas yang tidak mudah bagi seorang guru, karena untuk mengajarkan kapasitas tersebut gurunya pun harus dapat menggunakan kapasitas berpikir kritis dalam proses mengajar. Dalam sebuah penelitian yang dilakukan oleh Priatna (Fachrurazi, 2011) menunjukan, "Kapasitas berpikir kritis pesertadidik SMP pada Kota Bandung kurang begitu baik, yaitu hanya memperoleh skor $49 \%$ serta $50 \%$ dari skor ideal".

Studi pemula yang dilakuakan oleh Susilawati (Ramdhani, 2016) menunjukan, "Berpikir kritis matematik di lapangan masih rendah. Pemberian soal tes yang tidak begitu intens di lapangan sebenarnya sudah dilakukan, hanya saja persentase pesertadidik yang mengerjakan soal kapasitas berpikir kritis matematik kurang dari 10\%”. Telah banyak kita ketahui bahwa guru hanya berlamalama memaparkan sebuah materi pembelajaran, tetapi pesertadidik sebagai penerima ilmu tidak begitu memahami terkait materi yang dijelaskan oleh guru. Dan lebih ironisnya banyak guru tidak menyadari 
hal tersebut. Menurut Ruseffendi, (2006), "Salah satu faktor penyebab ketidakberhasilan belajar pesertadidik ialah terdapat dari kesalahan guru dalam penyajian ataupun metode pengajaran".

Melihat kenyataan dilapang, serta melihat berbagai permasalahan yang mulai bermunculan dalam pembelajaran matematika maka diperlukan metode yang baru dan atraktif agar dapat memperbaiki serta meningkatkan kualitas dan kuantitas suatu pembelajaran matematika melalui perbaikan-perbaikan proses pembelajaran. Diantara metode pembelajaran yang terdapat di duni pendidikan salah satu hal yang bisa memfasilitasi pesertadidik untuk menjalin kerjasama dan keaktifan adalah pendekatan CTL (kontekstual). Sakdiyah (2012) berpendapat bahwa, "Pendekatan kontekstual berorientasi kepada langkah-langkah yang telah guru persiapkan, lengkap dengan sumber dan materi pembelajaran yang akan diajarkan guna meningkatkan wawasan pesertadidik pada saat melaksanakan kegiatan belajar dan melibatkan komponen utama pembelajaran aktif”.

Pendekatan CTL dapat membuat pesertadidik mengaitkan materi pelajaran akedemik dengan konteks kehidupan sehari-hari untuk menemukan makna. Masitoh, dkk (2009) berpendapat, "CTL memperkaya kerangka berpikir pesertadidik lebih lanjut dengan memberikan pengalaman-pengalaman baru yang dapat merangsang kinerja otak guna merangkai hubungan baru untuk menemukan makna baru". Dalam pendekatan CTL terdapat tujuh komponen utama. Ketujuh tahapan pendekatan CTL tersebut menurut Suwangsih, E, dkk (2006), "Ketujuh tahapan tersebut ialah mengkonstruksikan, mendapatkan, menanya, bekerjasama memecahkan masalah, memberikan contoh, menggambarkan kembali, dan penilaian yang sebenarnya". Pada suatu kelas dapat dinyatakan telah mengaplikasikan pendekatan CTL bilamana ketujuh tahapan itu sudah dilaksanakan dalam proses pembelajarannya.

Pembelajaran CTL bisa dilaksanakan dalam kurikulum apapun, dalam bidang mata pelajaran apapun, dan pada keadaan kelas yang bagaimanapun. Maka dengan demikian pembelajaran CTL dapat dinyatakan metode pedapat dinyatakan yang fleksibel, tidak terikat, serta bisa dilaksana dalam keadaan apapun. Tugas ini berarti menjadi tantangan bagi guru matematika agar dapat menemukan pola atau cara-cara untuk membuat matematika berarti dan sangat diminati oleh anak-anak dan mudah untuk di mengerti. Menurut Hendriana (2015) berpendapat bahwa, "Salah satu cara yang sangat menjanjikan untuk melakukan ini adalah dengan menciptakan langkah-langkah di mana orang bisa berpikir tentang konsep-konsep matematika dalam hal-hal yang mereka sudah mengerti”.

Berdasarkan ulasan tersebut, peneliti mencoba melakukan penelitian dengan tujuan menelaah pencapaian kapasitas berpikir kritis matematik pesertadidik yang pembelajarannya mengaplikasikan pendekatan CTL dengan perbandingan pesertadidik yang mengaplikasikan pembelajaran biasa, dan peningkatan kapasitas berpikir kritis matematik pesertadidik yang mengaplikasikan pendekatan CTL dengan perbandingan pesertadidik yang mengaplikasikan pembelajaran biasa.

\section{METODE}

Teknik yang dilaksanakan pada proses penelitian yaitu dengan metode riset, dimana terdapat dua pengelompokan kelas yaitu satu kelompok kelas peninjauan dan satu kelompok kelas riset. Kedua kelompok kelas menerima soal pretes dan postes. Sebagai bentuk perlakuannya, kelas peninjauan akan diberikan materi matematika mengaplikasikan metode pembelajaran pendekatan biasa, sedangkan untuk kelas riset akan diberikan materi matematika mengaplikasikan metode pembelajaran pendekatan CTL. Dengan desain menurut Ruseffendi (2005), sebagai berikut: 
A : $0 \times 0$

A : $0 \quad 0$

Keterangan:

A: Pengambilan sampel sembarang menurut kelas

$0:$ Pretes $=$ Postes kapasitas berpikir kritis

$\mathrm{X}$ : Pengajaran matematika dengan metode pembelajaran pendekatan CTL

Populasi pada penelitian ini yaitu seluruh SMP di Kabupaten Bandung Barat, dipilih sembarang dan terpilih SMP Darul Hikmah. Sampel diambil sembarang kelas terpilih kelas VII A sebagai kelas riset, dan kelas VII B sebagai kelas peninjauan. Untuk memperoleh data dari proses penelitian tersebut, maka digunakan beberapa macam instrumen, yaitu seperangkat tes soal kapasitas berpikir kritis matematik. Agar bisa dilihat tingkatan kapasitas berpikir kritis matematik pesertadidik pada tahan awal sebelum pembelajaran dan sesudah kegiatan pembelajaran berlangsung, kemudian melakukan analisis gain ternormalisasi menurut Hake (Akmalia dan Jumiati, 2011),

$$
g=\frac{\text { skor tes akhir }- \text { skor tes awal }}{\text { skor maksimum ideal - skor tes awal }}
$$

Dengan kriteria indeks gain menurut Hake (Akmalia dan Jumiati, 2011):

Tabel 1. Klasifikasi Gain (g)

\begin{tabular}{cc}
\hline Besarnya g & Tingkat Gain Ternormalisasi \\
\hline $\mathrm{g} \geq 0,7$ & Tinggi \\
$0,3 \leq \mathrm{g}<0,7$ & Sedang \\
$\mathrm{g}<0,3$ & Rendah \\
\hline
\end{tabular}

\section{HASIL DAN PEMBAHASAN}

Hipotesis yang terdapat dalam penelitian ini yaitu "pencapaian kapasitas berpikir kritis matematik pesertadidik SMP yang mengaplikasikan pendekatan CTL lebih bagus hasilnya dibandingkan yang mengaplikasikan pendekatan pembelajaran matematika biasa dan peningkatan kapasitas berpikir kritis matematik pesertadidik SMP". Setelah melaksanakan proses pembelajaran dengan mengaplikasikan pendekatan CTL di kelas riset dan mengaplikasikan pembelajaran biasa di kelas peninjauan. Untuk pengujian hipotesis tersebut, maka dilakukan pengolahan data untuk menelaah pencapaian kapasitas berpikir kritis matematik pesertadidik SMP yang mengaplikasikan pendekatan CTL dengan pesertadidik yang mengaplikasikan pembelajaran biasa sesudah mendapatkan tindakan pembelajaran. Tabel 2 memuat masing-masing dengan data deskriptif kelas yaitu: 
Tabel 2. Data Deskriptif Kapasitas Berpikir Kritis Matematik

\begin{tabular}{|c|c|c|c|c|c|c|c|}
\hline \multirow{2}{*}{ Variabel } & \multirow{2}{*}{$\begin{array}{c}\text { Data } \\
\text { Statistik }\end{array}$} & \multicolumn{3}{|c|}{ Kelas Riset } & \multicolumn{3}{|c|}{ Kelas Peninjauan } \\
\hline & & Pretes & Postes & Gain & Pretes & Postes & Gain \\
\hline & $\mathrm{N}$ & & 38 & & & 38 & \\
\hline $\begin{array}{c}\text { Kapasitas } \\
\text { Berpikir } \\
\text { Kritis }\end{array}$ & Rerata & 6,947 & 20,211 & 0,722 & 5,684 & 18,026 & 0,632 \\
\hline Matematik & $\begin{array}{l}\text { Standar } \\
\text { Deviasi }\end{array}$ & 2,168 & 2,632 & 0,168 & 1,787 & 2,686 & 0,155 \\
\hline
\end{tabular}

Dari Tabel 2 di atas dapat dilihat perbedaan kapasitas berpikir kritis antara kelas riset dan kelas peninjauan tidak ada perbedaan yang signifikan, dari tes awal (pretes) yang dilaksanakan didapat rerata kelas riset adalah 6,947 dengan standar deviasi 2,168, sedangkan untuk rerata pretes kelas peninjauan adalah 5,684 dengan standar deviasi 1,787. Setelah mendapatkan metode pembelajaran yang berbeda untuk masing-masing kelas, kemudian pesertadidik diberikan kembali soal tes akhir (postes) untuk mengukur peningkatan kapasitas berpikir kritis matematik pesertadidik. Maka didapat hasil rerata postes kelas riset adalah 20,211 sedangkan untuk kelas peninjauan adalah 18,026. Untuk standar deviasi dari masingmasing kelas tidak mengalami perbedaan yang cukup signifikan yaitu 2,632 untuk kelas riset dan 2,686 untuk kelas peninjauan. Dan untuk hasil data tes gain dari kelas riset mendapat hasil 0,722 dan kelas peninjauan mendapat hasil 0,632.

Untuk mendukung deskripsi pencapaian kapasitas berpikir kritis matematik yang telah dijelaskan, maka dilakukan alanalisis data pencapaian kapasitas berpikir kritis matematik pesertadidik melalui uji statistik dengan mengaplikasikan tes yang membedakan dua rerata sebagai berikut:

a. Tes Normalitas Gain

Pengujian normalitas data mengaplikasikan uji Kolmogorov Smirnov dalam nilai signifikasi 5\%. Kriteria pada saat pengujian hipotesis tes normalitas yaitu:

Jika nilai signifikansi $>0,05$ maka $\mathrm{H}_{0}$ bisa diterima

Jika nilai signifikansi $\leq 0,05$ maka $\mathrm{H}_{0}$ tidak menerima

Dari hasil perhitungan dengan bantuan software IBM SPSS Statistic 23 maka diperoleh hasil:

Tabel 3. Hasil Tes Normalitas Data Gain Ternormalisasi

Tests of Normality

\begin{tabular}{|c|c|c|c|c|}
\hline \multirow[t]{2}{*}{ Kelas } & & \multicolumn{3}{|c|}{ Kolmogorov-Smirnov ${ }^{a}$} \\
\hline & & Statistic & Df & Sig. \\
\hline \multirow[t]{2}{*}{ Gain } & Riset & 0,227 & 38 & $\mathbf{0}$ \\
\hline & Peninjau & $\mathbf{0 , 3 2 1}$ & 38 & $\mathbf{0}$ \\
\hline
\end{tabular}

Berdasarkan Tabel 3, didapatkan nilai signifikan untuk kelompok kelas riset adalah 0,000 dan kelompok kelas peninjauan adalah 0,000. Karena nilai signifikasi kelas riset lebih kecil dari 0.05 maka $\mathrm{H}_{0}$ tidak menerima yang berarti sampel kelas riset tidak berdistribusi normal, serta nilai signifikansi kelas peninjauan lebih besar dari 0,05. Jadi $\mathrm{H}_{1}$ bisa diterima dengan artian sampel kelas peninjauan berdistribusi normal. Karena salah satu 
sampel pada kelas riset dan peninjuan tidak berdistribusi normal, maka tidak dilakukan uji homogenitas varians melainkan dilakukan tes non-parametrik Mann-Whitney untuk menganalisis perbedaan peningkatan kapasitas berpikir kritis matematik pesertadidik kelas riset dan peninjuan.

b. Tes Mann-Whitney

Berikut adalah kriteria untuk menguji hipotesis penelitian:

$\mathrm{H}_{0}: m_{1} \leq m_{2}$

$\mathrm{H}_{1}: m_{1}>m_{2}$

Dengan mengambil taraf nyata $(\alpha)$ sama dengan $5 \%$, maka kriteria pengujiannya adalah:

Jika nilai signifikansi $>0,05$ maka $\mathrm{H}_{0}$ bisa diterima.

Jika nilai signifikansi $\leq 0,05$ maka $\mathrm{H}_{0}$ tidak menerima

Berikut ini adalah data hasil tes statistik non parametrik mann-whitney yang telah dilakukan dan dapat dilihat dalam table 4 yang disajikan adalah :

Tabel 4. Hasil Tes Perbedaan Dua Rerata Data Gain Ternormalisasi

\begin{tabular}{lr} 
& Test Statistics ${ }^{\boldsymbol{a}}$ \\
\hline Mann-Whitney U & Gain \\
Wilcoxon W & 496,000 \\
Z & 1237,000 \\
Asymp. Sig. (2-tailed) & $-2,395$ \\
\hline
\end{tabular}

a. Grouping Variable: Kelas

Berdasarkan data Tabel 4 di atas, nilai signifikansi untuk 2-tailed $=0,017$. Menurut (Uyanto, 2009) bahwa apabila peneliti melaksanakan tes hipotesis satu pihak (one tailed) maka nilai tersebut dibagi dua. Oleh karena itu, nilai signifikasi untuk 2-tailed wajib dibagi dua menjadi $0,017 / 2=0,0085$. Dikarenakan nilai signifikansi $<0,05$ atau $0,0085<0,05$ maka $\mathrm{H}_{0}$ tidak menerima dan $\mathrm{H}_{1}$ bisa diterima, artinya terdapat peningkatan kapasitas berpikir kritis matematik pesertadidik di tingkat SMP yang pembelajarannya mengaplikasikan pendekatan CTL lebih bagus diberbanding pesertadidik yang mengaplikasikan pembelajaran biasa.

\section{Pembahasan}

Pada bagian ini diuraikan pembahasan mengenai deskripsi penelitian yang telah dilaksanakan. Proses pembelajaran dilakukan sepuluh kali pertemuan, dan setiap pertemuan baik kelas riset maupun kelas peninjauan diberikan LKS untuk penunjang proses pembelajaran pesertadidik, serta sebagai bahan latihan untuk memudahkan pesertadidik dalam pembelajaran. Menurut Trianto (Purwatiningsi, 2013) bahwa, "LKS merupakan panduan bagi pesertadidik yang bisa dipakai sebagai alat pembantu untuk melakukan kegiatan penyelidikan dan pemecahan masalah".

Terlihat dari hasil analisis data yang telah dilakukan, menunjukkan selisih nilai rerata pretes yang tipis antara kelas riset dan kelas peninjauan, kemudian dilakukan uji statistik, mununjukkan tidak ada perbedaan rerata kapasitas awal kelas riset maupun kelas peninjauan. Kedua kelompok kelas diberikan materi yang sama yaitu pokok pembahasan bangun datar segitiga dan segiempat. Pada kelas eskperimen proses pembelajaran dilaksanakan dengan mengaplikasikan pendekatan CTL, pembelajaran yang dilakukan di kelas peninjauan 
mengaplikasikan pembelajaran biasa, yaitu pembelajaran yang biasanya diaplikasikan guru di sekolah tersebut.

1. Kapasitas Berpikir Kritis Matematik

Berdasarkan analisis data hasil pencapaian awal diperoleh rerata skor kapasitas berpikir kritis matematik pada kelas riset dan kelas peninjauan tidaklah berbeda secara signifikan, dengan demikian terlihat pada Tabel 2 menunjukan rerata perolehan kelas riset adalah 6,95 sedangkan kelas peninjauan adalah 5,68. Pada tahapan pelaksanaan pembelajaran di kelas riset, peneliti mengelompokan pesertadidik menjadi kelompok-kelompok kecil (4 sampai 5 pesertadidik), serta diberikan LKS untuk menstimulus pesertadidik bekerja sama berdiskusi dalam kelompok.

Hasil pengolahan dan analisis data postes menunjukkan bahwa pencapaian kapasitas berpikir kritis matematik pesertadidik kelas riset lebih bagus berbanding kelas peninjauan, yang artinya hipotesis dalam penelitian ini terbukti diterima yaitu "Pencapaian kapasitas berpikir kritis matematik pesertadidik di tingkat SMP yang pembelajarannya mengaplikasikan pendekatan CTL lebih baik daripada yang mengaplikasikan pembelajaran biasa".

Hal ini sama seperti penelitian yang sebelumnya dilakukan oleh Munika (2015) yang menyimpulkan bahwa, "Kapasitas berpikir kritis matematik pesertadidik yang diterapkan metode pembelajaran learning Cycle $5 E$ lebih tinggi berbanding pesertadidik yang diterapkan pembelajaran konvensional".

2. Implementasi Pembelajaran dengan Mengaplikasikan Pendekatan CTL

Tahap pembelajaran pada kelompok kelas riset dengan mengaplikasikan pendekatan CTL sudah sesuai dengan rencana. Menurut Yamin (2013) pendekatan CTL ini terdiri dari tujuh langkah yaitu kontruktivisme, menemukan, bertanya, masyarakat belajar, pemodelan, refleksi, dan penilaian yang sebenarnya. Dan pada kelompok kelas peninjauan mengaplikasikan pembelajaran biasa.

Sesudah diberikan tindakan pembelajaran yang berbeda kepada masing-masing kelompok sampel, kedua kelas pada akhir penelitian diberikan tes akhir (postes). Pada hasil tes Mann-Whitney data postes kapasitas berpikir kritis matematik pesertadidik SMP yang proses pembelajarannya mengaplikasikan pendekatan CTL lebih baik daripada yang mengaplikasikan pembelajaran biasa. Selain itu, hasil uji perbedaan rerata Gain ternormalisasi kapasitas berpikir kritis matematik pesertadidik SMP yang pembelajarannya mengaplikasikan pendekatan CTL lebih bagus berbanding yang mengaplikasikan pembelajaran biasa. Hal ini sama seperti penelitian yang dilakukan oleh Maulida, (2014) berpendapat bahwa, "Penerapan pendekatan CTL (Kontekstual) bisa meningkatkan keaktifan belajar matematika pesertadidik kelas 4 dalam semua aspek".

\section{KESIMPULAN}

Hasil penelitian yang sudah dilaksanakan untuk mengetahui peningkatan kapasitas berfikir kritis matematik pesertadidik SMP mengaplikasikan pendekatan CTL dapat disimpulkan halhal sebagai berikut:

1. Pencapaian kapasitas berpikir kritis matematik pesertadidik yang mengaplikasikan pendekatan CTL lebih baik dibandingkan pesertadidik yang mengaplikasikan pembelajaran biasa.

2. Peningkatan kapasitas berpikir kritis matematik pesertadidik yang mengaplikasikan pendekatan CTL lebih baik dibandingkan pesertadidik yang mengaplikasikan pembelajaran biasa.

3. Implementasi pembelajaran mengaplikasikan pendekatan CTL di kelas dapat berjalan dengan baik dan memberikan implikasi positif bagi pesertadidik, serta dapat mendorong 
pesertadidik untuk membangun pemahamannya sendiri tidak terpaku pada penjelasan guru.

4. Kesulitan-kesulitan yang dihadapi oleh pesertadidik saat memperoleh pembelajaran dengan mengaplikasikan pendekatan CTL dalam menyelesaikan soal-soal tes kapasitas berfikir kritis matematik yang terdapat pada indikator mengevaluasi situasi sistematis secara reflektif untuk kelas eksperimen dan kelas kontrol.

\section{DAFTAR PUSTAKA}

Afrilianto, M. (2012). Peningkatan Pemahaman Konsep dan Kompetensi Strategis Matematis Siswa SMP dengan Pendekatan Metaphorical Thinking. Infinity Journal, 1, 192-202.

Akmalia, D. Jumiati, M. S. (2011). Peningkatan Hasil Belajar Siswa dengan Menggunakan Model Numbereds Heads Together (NHT) pada Materi Gerak Tumbuhan di Kelas VIII SMP Sei Putih Kampar. Lextura, 2, 2.

Fachrurazi. (2011). Penerapan Pembelajaran Berbasis Masalah untuk Meningkatkan Kemampuan Berpikir Kritis dan Komunikasi Matematis Siswa Sekolah Dasar. Portal Jurnal UPI. Bandung: Edisi Khusus.

Hendriana, H. Soemarmo, U. (2014). Penilaian Pembelajaran Matematika. Cimahi: Refika Aditama.

Hendriana, H. (2015). Kemampuan Metaphorical Thinking Guru Dalam Mengembangkan Pembelajaran Matematika. Infinity Journal, 1, 10-16.

Maulida, L. (2014). Penerapan Pendekatan Contextual Teaching and Learning Untuk Meningkatkan Aktivitas Belajar Matematika di Kelas IV Min Parung. Jakarta: UIN Syarif Hidayatullah.

Munika, S. (2015). Pengaruh Model Pembelajaran Learning Cycle 5E Terhadap Kemampuan Berpikir Kritis Matematis Siswa. Jakarta: Tidak diterbitkan.

Purwatiningsi, S. (2013). Penerapan Metode Penemuan Terbimbing untuk Meningkatkan Hasil Belajar Siswa pada Materi Luas Permukaan dan Volume Balok. Jurnal Elektronik Pendidikan Matematika Tadulako, $1,1$.

Ramdhani, A. (2016). Pengaruh Pendekatan Model-Eliciting Activities Terhadap Kemampuan Berpikir Kritis Matematik Siswa SMP Negeri di Kota Cimahi. In Skripsi STKIP Siliwangi. Cimahi: Tidak diterbitkan.

Rohaeti, E. E. (2008). Pembelajaran dengan Pendidikan Eksplorasi untuk Mengembangkan Kemampuan Berpikir Kritis dan Kreatif Matematik Siswa SMP. Bandung: Tidak diterbitkan.

Ruseffendi, E. T. (2006). Pengantar kepada Membantu Guru Mengembangkan Kompetensinya dalam Pelajaran Matematika untuk Meningkatkan CBSA. Bandung: Tarsito.

Sakdiyah. (2012). Pengaruh Pendekatan Kontekstual Terhadap Hasil Belajar. Jurnal Serambi Ilmu, $7,1$.

Sumarmo, U. (2012). Bahan Belajar Mata Kuliah Proses Berpikir Matematik Program S2 Pendidikan Matematika STKIP Siliwangi 2012. Bandung: Tidak diterbitkan.

Suryani dan Agung. (2012). Strategi Belajar Mengajar. Yogyakarta: Ombak.

Suwangsih, E, dkk. (2006). Model Pembelajaran Matematika. Bandung: UPI PRESS.

Uyanto, S. (2009). Pedoman Analisis Data dengan SPSS. Bandung: Graha Ilmu.

Yamin. (2013). Paradigma Baru Pembelajaran. Jakarta: Referensi. 